\section{Human evolution}

\section{A gathering of our ancestors}

\section{from Bernard Wood}

THE word 'unique' is abused by us all, but is aptly applied to the 'Ancestors' programme mounted this year by the American Museum of Natural History (AMNH) in New York. Readers will doubtless be aware of the recent resurgence of the creationist movement and its attempts to influence both public opinion and, more importantly, the views of legislators. Scientists have counter-attacked in print but large organizations and institutions have, as always, found it more difficult to respond effectively to what amounts to an attack on the foundations of all scientific endeavour - namely, reason and evidence. The AMNH has not, however, been idle. Three of its curators, John Van Couvering, Eric Delson and Ian Tattersall, conceived the notion of an exhibit of original fossils which would show the public the evidence which enables palaeoanthropologists to trace the path, or paths, that have led to modern humanity. With the endorsement of UNESCO, the museum set about the task of persuading governments, museums and curators to loan their precious fossils. The excellent response - a tribute to the competence and tenacity of the organizers - has produced a spectacular exhibition, which opened to the public on 12 April and will run until September this year.

The designers have sensibly allowed the fossils to tell their own story. The legends are informative, authoritative, but concise, and the fossils have been displayed in a way that allows visitors to see and understand these remarkable documents of our past. Where important specimens were not made available, the organizers have made sensible use of casts to illustrate them. While one can understand the reluctance of curators to part with their fossils on the grounds of security, it is disappointing, but perhaps inevitable, that political considerations should have prevented the display of some material which is supranational in both its scientific importance and its social significance. There are no 'stars' in the exhibit, and all who see it will be impressed, perhaps moved, by different aspects.

What impressed me most were the specimens from the two ends of the time span: the early fossils from the Oligocene and the Miocene, and the late Neanderthals. The enigmatic cat-like skull of Aegyptopithecus and the face of Sivapithecus are mercifully unaware of how closely their every fissure and prominence is being analysed to seek evidence of affinities. The Neanderthals impress because, despite differences in size and geographical location, they all really do show the characteristic features of the face and vault. They are convincing evidence that morphologists can detect reliable marker features despite the potentially confusing background of intraspecific variation.

Although it is a major part, the exhibit is only one of three components of the Ancestors programme. The two others, a series of study sessions and a five-day symposium entitled 'Palaeoanthropology: the hard evidence', were held last month, and were sponsored by the AMNH with the support of the NSF and the Wenner-Gren and Leakey Foundations. Each study session provided an opportunity for the close study of five or six of the original fossils by as many palaeontologists. My original scepticism of the usefulness of such a scheme was, in large measure, unwarranted. In particular, the sessions made it possible to discuss points of interpretation with those who were expert either on particular anatomical regions, for example Y. Rak (Tel Aviv University) on the face, J. Laitman (Mt Sinai School of Medicine, New York) and W. Kimbel (Cleveland Museum of Natural History) on the cranial base and F. Grine (SUNY, Stonybrook) on the teeth, or on particular remains, such as R. Clarke (University of Witswatersrand) on SK 847 from Swartkrans and Stw 53 from Sterkfontein. These were truly workshops, and ideas were exchanged and debated in a spirit of collaboration which bodes well for future research.

A symposium which attempts a comprehensive review of hominid evolution from the Oligocene to the Holocene is too broad in its scope usefully to address any particular research problem, but three strands could be traced through the five days. The first was the quality and breadth of information about the temporal and palaeoenvironmental context of hominoid and hominid evolution. The second was the increased and welcome emphasis on studying variation within an anatomical region, across a wide range of fossil and extant forms, and the last was the increasing influence of phylogenetic analytical methods on hominid palaeontology.

Reports of research undertaken in the Potwar Plateau (D. Pilbeam, Harvard University), at Laetoli (reported by $\mathrm{J}$. Harris, Los Angeles County Museum), in the Omo Basin (F. Brown, University of Utah) and at the South African Cave sites (C. K. Brain and E. Vrba, Transvaal Museum) served to emphasize the importance of the contrasting, but complementary, contributions of the physical sciences and faunal analysis to evolutionary studies. Brown reported a combination of chemical and microscopic analysis which has demonstrated that an ash widespread in the Omo Basin is present in deep-sea cores taken from the Gulf of Aden. This is compelling evidence in support of the contention that the same ash is present at Hadar (which has been effectively leap-frogged by the marine sediment evidence) and is a powerful illustration of the potential of such techniques. $H$. Thomas and E. Vrba made thoughtful and impressive use of faunal evidence in their contributions. Thomas reviewed the evidence for two phases of Neogene dispersal across the land bridge(s) between Africa and Asia: one at about $18 \times 10^{6} \mathrm{BP}$ and the other at $15 \times 10^{6} \mathrm{BP}$. Vrba urged hominid palaeontologists to see hominids in the context of evolutionary changes occurring in other groups of land mammals. She associated, if not correlated, the marked peak in the rate of appearance of bovid species, and probably other groups as well, with a major change in climate. The apparent appearance at this time of Homo habilis and the 'robust' australopithecines suggests that hominids may have reacted in a similar, but more modest, way. It is therefore of some interest that at least one hominid palaeontologist suggested that the early phases of the evolution of Homo may have been more complex than usually presented. Vrba's admirable attempts to suggest a scenario for hominid evolution are, like many others, heavily influenced by the assumption that the hominids in Members 4 and 5 from Sterkfontein are taxonomically distinct, but more evidence will be needed before Stw 53, from Member 5, can be confidently included in Homo habilis.

There was evidence among some hominid palaeontologists of a move towards considering whether features are widely or narrowly distributed, and utilizing this, and additional, information to deduce morphoclines and thus clade groupings. But the shift towards this philosophy was stoutly resisted by others. Grade and clade arrangements rest on different premises. It is therefore pointless arguing about palaeontological details when at the heart of differences in interpretation are deeper philosophical divisions. Hominid palaeontology must, like other branches of palaeontology, see that its scientific dialogue is adjusted to take account of this. Cladists have to realize that a cladogram based on a narrow range of features stands an even chance of being unreliable when seen against the background of a comprehensive set of character states. Adherents of the classic 'Simpsonian' approach should also be aware that a concept such as the 'total morphological pattern' is often couched in such a general way that any systematic decisions based on it are essentially untestable.

Bernard Wood is Professor of Anatomy in the Department of Anatomy and Biology as applied to Medicine, The Middlesex Hospital Medical School, London WIP 6DP. 